\title{
A questão negra entre continentes: possibilidades de tradução intercultural a partir das práticas de luta?
}

MARIA PAULA MENESES*

\begin{abstract}
Resumo
Este artigo parte do desafio de que não é possível uma justiça social global sem justiça cognitiva. A partir da análise crítica das ondas de violência xenófoba que têm abalado comunidades negras vivendo na África do Sul, este artigo, cuja referência analítica assenta nas propostas teóricas avançadas por Boaventura de Sousa Santos a partir das Epistemologias do Sul, aponta para a urgência de uma leitura mais complexa e cuidada da diversidade e das hierarquias culturais, condição para uma tradução ampla do impacto da violência colonial. Assente numa reflexão sobre as discriminações raciais no Brasil e os conflitos xenófobos na África do Sul, este artigo busca propor pistas que contribuam para descentrar as narrativas eurocêntricas dominantes, apostando numa visão do social enquanto espaço plural, composto de múltiplas narrativas interligadas, frequentemente contraditórias entre si. A construção de um diálogo intercultural constitui, como este artigo defende na sua parte final, um desafio à compreensão ampla das raízes da desigualdade no mundo. Múltiplas experiências cosmopolitas caracterizam os atuais contextos urbanos no Sul global e o não reconhecimento desta vibrante e diversa realidade cultural e epistêmica constitui um compasso reivindicativo pelo ampliar dos sentidos da cidadania e das pertenças. ${ }^{1}$
\end{abstract}

Palavras-chave: África. Cidadania. Diversidade. Justiça cognitiva. Epistemologias do sul

\footnotetext{
* Centro de Estudos Sociais (CES) da Universidade de Coimbra (Portugal).

${ }^{1}$ Este artigo foi elaborado no âmbito do projeto de investigação "ALICE - Espelhos Estranhos, Lições Imprevistas: Definindo para a Europa um novo modo de partilhar as experiências do Mundo", coordenado por Boaventura de Sousa Santos (alice.ces.uc.pt) no Centro de Estudos Sociais da Universidade de Coimbra - Portugal. O projeto é financiado pelo Conselho Europeu para a Investigação, 7o Programa Quadro da União Europeia (FP/2007-2013) /ERC Grant Agreement n. [269807]. O meu agradecimento aos revisores anónimos, cuja crítica atenta permitiu restruturar o texto e fortalecer os argumentos.
} 
Sociologias, Porto Alegre, ano 18, no 43, set/dez 2016, p. 176-206

\section{The 'black man's question across continents: possible intercultural translation from the struggle practices?}

\section{Abstract}

This article is based upon the assumption that no global social justice may exist without a global cognitive justice. Through a critical analysis of the waves of xenophobic violence that have shaken black communities living in South Africa over the last years, this article, based upon the theoretical proposals of the Epistemologies of the South advanced by Boaventura de Sousa Santos, points to the urgency of a more complex and detailed understanding of cultural diversity and cultural hierarchies, conditions for a broader translation of the impact of colonial violence. From a reflection on racial discrimination in Brazil and xenophobic attacks in South Africa, this article seeks to decentralize the dominant Eurocentric narratives, betting on a social as plural space composed of multiple interconnected narratives, often contradictory. The construction of an intercultural dialogue as a means of translating among the struggles in the world is, as this article argues in its final part, a challenge to the wider understanding of the roots of inequality in the world. Various cosmopolitan experiences shape modern urban contexts in the Global South, and the non-recognition of this cultural and epistemic vibrant diversity exemplifies a pressing demand for a broader sense of citizenship and belonging.

Keywords: Africa. Citizenship. Diversity. Cognitive justice. Epistemologies of the south. 
Sociologias, Porto Alegre, ano 18, no 43, set/dez 2016, p. 176-206

A crise consiste precisamente no fato de o velho estar a morrer e o novo não ter ainda nascido; neste interregno, podem acontecer os mais variados fenómenos

mórbidos.

(Gramsci, 1996, p. 33)

\section{Introdução: do não-ser à luta pela reivindicação da humanidade}

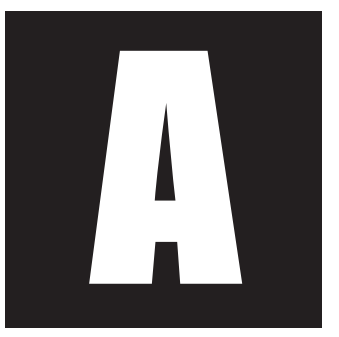

'questão do homem negro', 2 da sua humanidade, tem estado no centro dos debates pós-coloniais. Escrevendo no início da década de 1950, Frantz Fanon problematizava o carácter racial da epistemologia eurocêntrica, que constrói o negro como não-ser, desprovido de humanidade (1967, p. 7). Mas no nosso tempo, apesar da emergência de um projeto politica e epistemicamente alternativo - o Sul global ${ }^{3}$ - permanece refém da natureza hierárquica das relações Norte-Sul, relações assentes numa racionalidade moderna eurocêntrica, promotora de uma lógica capitalista, impessoal e devastadora, apoiada numa ordem política e económica desigual e assumidamente monocultural. É esta lógica que torna quase impossível reconhecer como iguais as vidas e as vozes dos que são concebidos como não-existentes.

\footnotetext{
${ }^{2}$ Metáfora que simboliza a opressão colonial e das violências exercidas sobre o continente africano.

${ }^{3}$ Este sul é extremamente diverso. A constituição do Sul global integra vários projetos políticos, incluindo a Conferência de Bandung, o Movimento dos Não-alinhados, a Tricontinental, e a constituição do Fórum Social Mundial. Visto desta perspetiva, o Sul global é um Sul geopolíti$\mathrm{Co}$, uma metáfora usada para identificar o conjunto de movimentos, de ações coletivas contra as formas de opressão, exploração e discriminação (Santos; Meneses, 2010).
} 
Restituir a humanidade ao 'homem negro', ultrapassar a exclusão epistémica e a negação ontológica a que tem estado sujeito, é uma das dimensões fundamentais de qualquer projeto de justiça. Enquanto desafio ético, a justiça cognitiva é uma condição para a mudança radical da injustiça trazida pelo projeto colonial-capitalista, onde a epistemologia, em lugar de ser singular, é vista como processo de negociação e diálogo entre saberes. As epistemologias do sul constituem um projeto político e metodológico com o objetivo de criar um mundo plural e dinâmico de infinitas possibilidades cognitivas, onde a ênfase está centrada na tradução de práticas, lutas e saberes (Santos, 2006, 2014). Realçando a centralidade desta luta para o nosso tempo, Paul Gilroy (2009) sublinha a importância de imaginar um mundo ético e justo onde se cumpra a promessa de humanismo. Esta mudança de imaginário exige um confronto direto com as realidades e heranças desconfortáveis produzidas pelo encontro colonial, incluindo as contínuas representações preconceituosas sobre a alteridade. Vista desta perspetiva, a dimensão epistémica da justiça - a justiça cognitiva - não pode ser reduzida a uma dimensão única, como é o caso da dimensão racial; o seu contexto é mais amplo, pois trata-se de problematizar a alteridade como projeto simultaneamente politico e epistémico, interrogando a forma como o conhecimento colonial produziu e continua a produzir alteridades excludentes.

A noção de humanidade como composta de uma série progressiva de estádios, em que os vários povos não europeus ocupavam os níveis inferiores, constituiria, nos séculos XVIII-XIX, a estrutura base que produziu a invenção de África e dos seus habitantes enquanto lugar de inferioridade. Esse pressuposto, associado à ideia da linearidade do progresso, gerou a ideia de que o estádio supremo do desenvolvimento - a civilização - era apanágio da Europa, do ocidente. A criação da alteridade enquanto um significado vazio, um objeto desprovido de conhecimentos e pronto a ser 
preenchido pelo saber e cultura eurocêntricas, foi o contraponto de uma reivindicação colonial que justificava como 'dever moral' transportar a civilização e a sabedoria para povos vivendo supostamente nas trevas da ignorância (Meneses, 2011). É esta relação que, ao aliar a empresa colonial ao projeto capitalista, simboliza a dominação política e cultural colonial: "é-se rico porque se é branco, e é-se branco porque se é rico" (Fanon, 1963: 40). A segmentação abissal da sociedade colonial entre 'civilizados' e 'selvagens', entre humanos e não-humanos, conferiu consistência a todo o projeto colonial, ao transformar os africanos negros em objetos naturais, sobre quem urgia agir, para os 'introduzir' na história (Meneses, 2011).

A representação colonial do 'negro', construída nos últimos séculos, tem sido persistentemente desafiada desde diferentes lugares de luta, resultando em propostas epistémicas e ontológicas que desafiam esta representação. Aimé Césaire (1947), por exemplo, argumentava que o destino do 'homem negro' teria de passar pela rejeição de qualquer imagem construída sobre si, desafiando as representações que o mostravam como incapaz de ter saberes, de construir qualquer civilização. Porém, muitas destas lutas, destas reivindicações e experiências não têm encontrado eco na moderna academia eurocêntrica. Em paralelo, e apesar de partilharem elementos comuns (denúncia da opressão colonial-capitalista, por exemplo) os diálogos entre estas lutas, que ocorrem em vários contextos e que vêm marcando de forma definitiva o panorama social americano e africano, não conhecem ainda a centralidade que merecem.

No contexto brasileiro, por exemplo, a reivindicação do direito à história ampla do contributo negro na construção do Brasil tem sido uma das principais reivindicações do movimento negro (Silva et al., 2003), associada a uma luta apostada em ações afirmativas e pela representatividade do 'negro' no espaço público (Brandão, 2007). Como várias vozes têm advogado, a luta contra a discriminação racial continua a ser um dos eixos do processo descolonial brasileiro (Munanga, 2004; Gomes, 2012). 
Do outro lado do Atlântico, em África, a questão colonial tem colocado inúmeros desafios, que têm atraído a atenção dos seus intelectuais. De entre os temas, encontra-se a crítica ao eurocentrismo e a centralidade africana/ negra na História do mundo, ${ }^{4}$ os debates sobre a filosofia africana, ${ }^{5}$ etc. Para muitos intelectuais africanos, qualquer projeto emancipatório deve desafiar qualquer que seja o 'centro' epistémico - contribuindo para a libertação de culturas do mundo de ratoeiras feitas a partir de uma leitura singular, como o nacionalismo, classe, raça ou género (Thiong'o, 1993, p. xvii).

Neste artigo, cuja referência analítica assenta nas propostas teóricas avançadas por Boaventura de Sousa Santos - tais como o pensamento abissal, a sociologia das ausências e das emergências, e a tradução intercultural - procuro analisar as razões das repetidas ondas de violência xenófoba que têm abalado comunidades negras vivendo na África do Sul. Ao tornar visíveis os conflitos herdados do passado colonial, este texto procura dar corpo e espaço a realidades vividas tornadas ausentes por processos de invisibilização, silenciamento e subalternização, expondo os processos que estão na sua origem (Santos, 2002, p. 246). Como Santos sublinha, a sociologia das ausências exige, neste domínio, o exercício de uma imaginação cartográfica, quer para ver em cada escala de representação não só o que ela mostra, mas também o que ela oculta, quer para lidar com mapas cognitivos que operam simultaneamente com diferentes escalas, nomeadamente para detetar as articulações locais/globais. É a partir deste mútuo conhecimento, assente em análises mais detalhadas dos conflitos sobre a alteridade, que se desenvolvem diálogos contemporâneos entre iguais, forja de alianças de forças pan-africanas. ${ }^{6}$

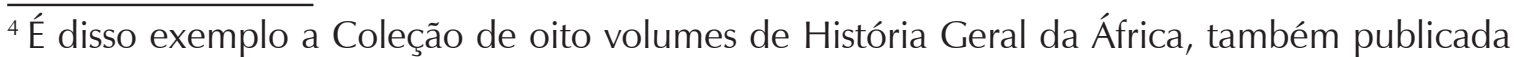
em português (edição conjunta da UNESCO - Representação no Brasil; Ministério da Educação do Brasil e Universidade Federal de São Carlos).

${ }^{5}$ Veja-se, entre outros, Mudimbe, 1988; Hountondji, 1997; Ramose, 2003.

${ }^{6} \mathrm{O}$ Pan-africanismo, como projeto político apela à unidade de todos os africanos, almejando o reconhecimento e emancipação política dos africanos e da diáspora africana.
} 
O argumento central deste artigo é que a descolonização, ao exigir o direito à história, para além da narrativa eurocêntrica, desdobra-se em dois desafios principais: um, de natureza ontológica - a renegociação das definições do ser e dos seus sentidos - e, outro, epistémico, que contesta a compreensão exclusiva e imperial do conhecimento (Meneses, 2009, 2016). Na primeira parte, este artigo percorre rapidamente a problemática do saber eurocêntrico sobre África, saber que Valentin Mudimbe apelida de "biblioteca colonial". Como este autor alerta (1988, p. 208), parte significativa do saber sobre o continente africano continua refém de representações produzidas tendo como referência saberes eurocêntricos coloniais, impossibilitando uma leitura intercultural - pluriversalista e polirracional - do mundo. Na segunda parte, o artigo examina as razões dos ataques xenófobos na África do Sul, para, a partir desta análise, procurar articular pontes com as situações de discriminação racial vividas no Brasil, como base para um diálogo intercultural situado em torno aos sentidos de pertença. Na parte final, o artigo debruça-se sobre os sentidos da comunidade política, dos conteúdos e formas de cidadania. No contexto pós-apartheid sul-africano, a cidadania foi reduzida à questão 'nativa', ou seja, as pessoas nascidas na África do Sul têm direito preferencial aos recursos do país, antes de qualquer estrangeiro residente ou cidadão não-originário. Numa análise detalhada deste processo, Michael Neocosmos (2010) mostra que apenas quem pôde provar uma ligação familiar, ainda durante o período do apartheid, pôde reivindicar a cidadania no período da libertação. Todos os outros africanos que habitavam a África do Sul e que têm continuado a chegar ao país foram excluídos e a sua solicitação à pertença nacional e aos recursos do país é vista como injustificada. Através da definição de quem é cidadão e quem não é, o Estado sul-africano tem vindo a desempenhar um papel central neste processo. Porque a xenofobia está intimamente ligada à cidadania, erradicar a xenofobia passa pelo redefinir e ampliar o sentido de pertença, o sentido de cidadania. 


\section{Entre centros e periferias - a localização da alteridade}

As lutas pelo alargamento dos sentidos de pertença são lutas fundamentais pela (re)definição das condições de presença e de cidadania. Discutir a história de África no contexto amplo das lutas pan-africanistas é uma forma de ampliar as possibilidades de diálogo intercultural, colocando ideias ao serviço da humanidade e promovendo a descolonização da ideia de cidadania, através do alargar de oportunidades cosmopolitas sobre a infinidade de sentidos de pertença.

O capitalismo industrial moderno, o estado-nação (e as suas instituições) e a cultura da modernidade eurocêntrica chegam à África subsaariana como parte de um projeto amplo, articulando o capitalismo com a intervenção colonial. Como consequência, as formas complexas que estão na origem de muitas das referências sobre o Sul global são produtos de perceções exógenas ao continente, perceções que construíram categorias eurocêntricas para se compreender a violência associada à 'situação colonial'. Hoje ainda, um dos problemas centrais com que as ciências sociais em contexto africano se deparam é sobre a capacidade dos africanos se autorrepresentarem: como produzir uma autodefinição recorrendo a conhecimentos e referências essencialmente exógenos? Adicionalmente, se o conhecimento em que estas representações assentam, e as lutas a elas associadas, são vistas numa perspetiva singular, há um forte risco de estas representações sobre a diversidade continuarem a recorrer a um conhecimento produzido não por africanos mas sobre os africanos, um conhecimento que os (re)produz como naturalmente inferiores e incapazes de se libertarem, por si sós, da barbárie em que se encontram. E esta inferioridade é muito difícil de ser superada (Mbembe, 2002, p. 242; Meneses, 2011, p. 124-125). Neste sentido, a (re)conquista do poder de narrar a própria história - e, portanto, de construir a sua imagem, a sua identidade, de recuperar e assumir uma diversidade de saberes - tem de 
passar por um diálogo crítico sobre as raízes das representações contemporâneas, questionando a geopolítica do poder na origem dos conceitos como tribo, raça, nação, etc.

A persistência de saberes reféns das perspetivas que sustentam a biblioteca colonial, saberes forjados no centro de um saber de matriz eurocêntrica, continuam a reforçar a permanência de perspetivas do Norte sobre o Sul (Hountondji, 1997, p. 237; Ramose, 2003, p. 600). Este posicionamento teórico, político e metodológico é a afirmação de uma única ontologia, de uma epistemologia exclusiva, cujas tentativas de universalização importa analisar. Como vários autores sublinham, a história da modernidade assenta, num primeiro momento, na criação do espaço-tempo eurocêntrico como excecional, transformando-se o mundo colonial como externo e anterior ao momento do progresso da Europa (Thiong'o, 1993, p. xvi; Bhabha, 1994, p. 250). O resto do mundo foi, e continua a ser assumido como periférico e anterior aos processos histórico-mundiais sob consideração. Concretamente, os processos coloniais e os episódios de violência a estes associados são apagados, secundarizados ou silenciados.

No caso africano, o resultado da apropriação política, económica e científica do continente pela máquina colonial moderna assentou na negação do reconhecimento da diversidade que o conceito 'África' esconde e olvida. A 'nova' África mapeada pelos saberes coloniais construiu o africano como objeto, situando eternamente num plano temporal anterior aos alcances do conhecimento do Norte global. Samir Amin (1989), que desde há muito tem vindo a criticar e a desafiar o eurocentrismo que predomina nas ciências sociais, tem apelado, em sintonia com Etienne Balibar (2004), à premência de desacoplar a 'Europa' do projeto 'universal'. Este desacoplar permite uma crítica substantiva à 'situação colonial' enquanto paradigma, ou seja, um conjunto de axiomas, conceitos e discursos através dos quais se procura representar o continente africano, 
como um objeto de conhecimento, através de olhos e saberes europeus. A crítica ao eurocentrismo, ou a qualquer saber que, a partir do seu lugar de referência, se queira assumir como tendencialmente universal, é fundamental, pois qualquer proposta universalista nega a possibilidade de racionalidades ou histórias plurais (Mudimbe, 1988, p. 208).

A criação da alteridade como espaço/tempo anterior, onde circulavam saberes inferiores próprios de povos inferiores, foi o contraponto da exigência colonial de transportar a civilização e a sabedoria para povos vivendo supostamente nas trevas da ignorância. Esta estruturação hierárquica está na base da estruturação ontológica e epistémica do moderno pensamento científico, relação que opera pela permanente imposição de um pensamento abissal que divide o mundo em duas partes (Santos, 2007, p. 46-47): o mundo moderno ocidental, de um lado, e os 'outros' espaços, coloniais, da tradição, dos primitivos, do 'outro' lado. As realidades que ocorriam no espaço colonial não comportavam as normas, os conhecimentos e as técnicas aceites no velho mundo civilizado. E esta linha abissal, que separa os humanos dos sub-humanos continua a gerar exclusões abissais, como se debaterá na secção seguinte.

O impacto destas relações epistémicas desiguais impostas pela razão colonial eurocêntrica permanece nos dias de hoje, assinalando a persistência de relações e interpretações coloniais que limitam as leituras sobre o Sul global, quer a nível epistémico (os 'outros' não sabem pensar, ou o seu pensar não é tão sofisticado como), quer a nível ontológico (os 'outros' não contam). Esta perda de autorreferência legítima não foi apenas uma perda gnosiológica, foi também, e sobretudo, uma perda ontológica: as referências e saberes africanos ficaram circunscritos ao espaço africano (Meneses, 2009), situado do outro lado da linha abissal, agora designados de saberes tradicionais e locais. 
Para superar a condição epistémica eurocêntrica, para ultrapassar a condição de exclusão abissal gerada pela relação colonial, importa ampliar o nosso conhecimento da diversidade de experiência no mundo. Para tal, como salienta Boaventura de Sousa Santos, é fundamental

ir para o Sul e aprender com o Sul, mas não o Sul imperial (que reproduz, no Sul, a lógica do Norte tomada como universal); ao invés, procura aprender do Sul anti-imperial (metáfora do sofrimento humano sistemático e injusto provocado pelo capitalismo e colonialismo globais e do fruto da resistência contra estes) (2008, p. 267).

O espaço dos saberes produzidos por quem tem sido alvo de opressão, exploração e discriminação é o espaço das Epistemologias do Sul. Neste sentido, é um conhecimento nascido na luta no/do Sul global, onde múltiplas epistemologias rivalizam, interpenetram e dialogam entre si (Santos; Meneses, 2010, p. 10).

O reconhecimento dos saberes do Sul global é fundamental para mostrar efetivamente que a realidade do mundo é muito mais ampla do que aquilo que o conhecimento dominante nos dá como existente e como possível, o que obriga a diálogos amplos entre várias formas de compreender e explicar o mundo. ${ }^{7}$ Boaventura de Sousa Santos (2006) designa o diálogo entre saberes de ecologias de saberes, defendendo que, neste diálogo, os saberes só podem ser explorados e valorizados, se comparados com outros saberes, em situações semelhantes de poder e cuja experiência se traduz em narrativas espessas (Geertz, 1973, p. 3-4). Este diálogo, tendencialmente horizontal, possibilita, por um lado, ampliar perspetivas e conceções sobre o conhecimento, o poder e o ser, para além das marcas coloniais (Santos; Meneses, 2010, p. 7-10); por outro

\footnotetext{
${ }^{7}$ Como argumento noutros textos, a modernidade eurocêntrica, dominada pela razão metonímica, não só tem uma compreensão limitada do mundo, como tem uma compreensão limitada de si própria (Santos, 2002).
} 
lado, permite abrir caminho para uma reflexão sobre a diversidade de processos de 'descolonização' do ser e dos seus saberes, condição fundamental para traduções interculturais ${ }^{8}$ como alternativas a uma teoria geral (Santos, 2006). Em lugar de uma teoria geral, para Boaventura de Sousa Santos, a tradução intercultural emerge como o mecanismo capaz de gerar uma inteligibilidade mútua entre experiências possíveis e disponíveis. E é esta a importância da promoção de um diálogo entre as lutas que, quer nas Américas, quer em África, enfrentam o colonialismo, o racismo e a negação do ser e da história do 'homem negro' e de África, lutas que continuam a marcar o projeto pan-africano. Fundada a partir das experiências coloniais nas Américas, na Europa e em África, cada uma destas experiências apresenta especificidades intelectuais, políticas, sociais e culturais, apontando a impossibilidade de se reduzir o ideal pan-africano a uma das suas partes: sem África, as diásporas africanas perdem a sua identidade; sem as diásporas, África arrisca-se a perder de vista a amplitude da sua contribuição para o mundo, bem como as suas responsabilidades. Mas a força do conjunto das lutas tem sido fundamental no apoio às propostas emancipatórias pan-africanas.

A articulação da ideia de uma ampla revolução contra a presença colonial - a luta contra todas as formas de discriminação económica, racial e cultural - é um dos elementos fundacionais do moderno pan-africanismo (M’bokolo, 2003). O conhecimento das raízes, traduzido em sentido histórico, associado a uma sensibilidade forte da estrutura política do mundo, permitiu-lhes desenvolver uma nova proposta política, articulando uma noção mais ampla do tempo: o passado (reivindicação da contribuição africana - incluindo a sua diáspora - à história do mundo),

\footnotetext{
${ }^{8}$ Para Boaventura de Sousa Santos (2006), a tradução intercultural corresponde aos procedimentos de busca de proporção e correspondência que permitam aproximações entre saberes, de modo recíproco, onde saber algum ocupa um lugar dominante.
} 
o presente (as inovações trazidas pelas propostas radicais a partir das lutas nos vários contextos) e o futuro (prevista na construção de uma África independente - Nkrumah, 1961, p. xi -xiv).

Longe de um projeto fechado e apertado, o manifesto intelectual do pan-africanismo defendeu a plena participação da África no mundo, onde uma das componentes centrais foi o apoio solidário à luta pela unidade dos povos colonizados - na sua diversidade. Todavia, se esta proposta radicaliza a agência africana, o surgimento de África como o 'continente negro' reflete uma conceção limitadora e homogeneizante da estrutura política e cultural do continente. Criticando este excesso de nativismo que ainda percorre a proposta ideológica pan-africana, Achille Mbembe (2002) destaca como o pensamento social pan-africano gerou um historicismo debilitante sob a forma de uma antinomia entre duas correntes de pensamento: a 'afro-radical' e a da 'metafísica da diferença', ou seja, o nativismo. Para Mbembe, o traço característico destas correntes é uma fixação em três eventos históricos emblemáticos e violentos: a escravidão, a colonização e o apartheid, vistos como perversos e exógenos, símbolo de um mal radical. O resultado deste mal foi a alienação do 'eu' Africano de si mesmo, a sua desapropriação material e degradação espiritual - a tomada do território e da alma nativa. Mas o aspeto mais problemática do 'afro-radicalismo' e do 'nativismo' reside no facto de qualquer uma destas propostas procurar iludir a avaliação das condições internas presentes em África, repelindo a responsabilidade africana dos desastres que acontecem no continente, já que ambas as correntes thes atribuem uma origem exógena. Um grave erro destas abordagens resulta do facto de renunciarem à possibilidade de uma reflexão filosófica quer sobre a condição africana (Mbembe, 2002, p. 251), quer da relação desta condição com questões ontológicas e epistemológicas. 
Uma problematização mais ampla da condição 'do negro' não conflui para um desmembramento do pan-africanismo; pelo contrário, passa pela afirmação da diversidade das lutas e da necessidade de tradução das mesmas, para, no seu conjunto, contribuírem para a descolonização das representações. A reabilitação da singularidade e a diferença de cada projeto político, a partir das próprias referências (autodefinição), transforma-se numa das condições centrais do diálogo dentro deste amplo movimento, num movimento oscilante que permite analisar a experiência africana sem a considerar excecional, evitando, em paralelo, mergulhar a estrutura intelectual do movimento num pacote teórico tão generalista que descaracterize as experiências específicas. Este é um dos grandes desafios no presente: o reconhecimento da liberdade política e dos projetos de emancipação cultural como projetos situados, fruto de situações concretas, reconhecendo os territórios e as suas histórias de luta como condição fundamental para compreender a construção de categorias teóricas como colonialismo ou descolonização, categorias essenciais à ação política e ao diálogo intercultural.

\section{Xenofobia como latência do projeto colonial-capitalista?}

Um pouco por toda a parte no continente africano, os processos de retorno democrático ao multipartidarismo e de descentralização política têm vindo a abrir espaço para um questionamento sobre a cidadania, sobre identidades. Na África do Sul, nos Camarões, na Costa do Marfim, no Quénia ou em Moçambique, hierarquias e dicotomias estruturam a relação íntima do corpo africano com a cidadania, através de múltiplos sentidos de pertença, estruturados em raça, etnicidade, classe, género, e geografia. Estas dicotomias - quem é ou não cidadão - jogam um papel estruturante nas mãos de políticos e elites políticas e económicas sem escrúpulos, em detrimento dos direitos humanos e dignidade. 
Que é cidadão? Quem pode votar? Quem pertence realmente a uma comunidade e pode beneficiar-se da justiça social? Estes novos veIhos problemas identitários surgem na onda de um longo processo histórico, em que as marcas do encontro colonial jogam um complexo papel, como a realidade sul-africana ilustra. Aqui, uma nota preliminar é fundamental: nem a xenofobia é sinónimo de racismo, nem o racismo é sempre xenófobo. Se o racismo, assente em relações de poder coloniais, atribui uma superioridade e inferioridade naturais a determinados grupos sociais a partir de características físicas ou relações de ancestralidade, a xenofobia recorre a marcadores imaginários do 'estrangeiro', a incompatibilidades culturais ou religiosas para justificar situações de exclusão (Adam; Moodley, 2014, p. 21).

A Copa do Mundo de Futebol de 2010, realizada na África do Sul, foi entusiasticamente apresentada como uma Copa do Mundo africano. No entanto, na África do Sul real a vida é distinta. A violência contra estrangeiros e comunidades migrantes é uma característica da vida contemporânea, tendo as mais dramáticas manifestações tido lugar em 2008 e 2015. ${ }^{9}$ Mas talvez a xenofobia não dê conta da especificidade da violência estruturada contra os estrangeiros na África do Sul, pois os brancos estrangeiros não são, normalmente, o foco destas manifestações de ódio. Pelo contrário, os brancos e asiáticos são vistos como elementos importantes para a eco-

\footnotetext{
${ }^{9}$ Durante cerca de vinte dias, em Maio de 2008, um pouco por toda a África do Sul, as favelas das principais cidades conheceram uma onda sem precedentes de violência xenófoba que deixou 62 pessoas mortas e produziu de 30.000 deslocados internos. Várias pessoas foram presas e condenadas na sequência destes ataques. Os ataques de 2015 conheceram menos vítimas. Sobre este tema, veja-se, por exemplo, South African mob kills migrants disponível em http:// news.bbc.co.uk/2/hi/africa/7396868.stm. Acesso em: 27 dez. 2015; South Africa: Xenophobic Rage Leaves Trail of Havoc in Gauteng disponível em http://allafrica.com/stories/200805190001. html. Acesso em: 27 dez. 2015; Murderous xenophobia disponível em http://www.dandc.eu/en/ article/impact-xenophobic-violence-south-africa-has-zimbabwe. Acesso em: 23 dez. 2015 e Living in fear after attacks on migrants in South Africa disponível em http://www.pbs.org/newshour/ bb/living-fear-attacks-migrants-south-africa/. Acesso em: 23 dez. 2015.
} 
nomia e cultura do país (Nyamnjoh, 2006, p. 28). O alvo preferencial dos ataques xenófobos tem sido essencialmente negros oriundos de países vizinhos, normalmente apelidados de 'makwerekwere', uma expressão local usada para fazer referência ao emigrante como o outro desprezível, cuja língua não é inteligível aos sul-africanos. ${ }^{10} \mathrm{Em}$ poucas palavras, no contexto sul-africano a xenofobia tem vindo a assumir crescentemente contornos de afrofobia, como Trevor Ncube (2015) sublinha.

Os municípios sul-africanos são hoje, como noutros contextos africanos, espaços de intensa experimentação cosmopolita. Porém, face à longa tradição das categorias subjetivas de raça, etnicidade e nacionalismo, estes encontros em cidades repletas de dinâmicas culturais e de diversidade não são fáceis nem simples. A violência e a hostilidade permanente são elementos que, para Franz Fanon, caracterizam o estado natural da dominação colonial (1963, p. 61). O projeto político sul-africano pós-apartheid não rompeu as relações sociais bifurcadas herdadas do passado; pelo contrário, a sociedade continua a estar estruturada em torno do nexo brancos e classe média negra $=$ humanos $/$ maioria negra $=$ sub-humanos. Esta estrutura social está de tal forma presente na experiência cotidiana que a política continua a ser sustentada por meio da opressão racial, da exclusão social, e da invisibilização das necessidades da maioria negra. É esta 'desumanização' que fratura abissalmente a mole humana africana, ao transformar o sujeito colonial num ser sub-humano (Fanon, 1963, p. 42). Subjacente a esta exclusão está a ideia que os sub-humanos não poderão jamais aspirar a transpor a linha que os separa dos humanos.

Não é fácil destacar os fatores dominantes que alimentam a xenofobia nas sociedades contemporâneas. No caso sul-africano, a sua especificidade parece residir no facto de o antagonismo e ressentimento contra

\footnotetext{
${ }^{10}$ Este grupo integra igualmente comerciantes informais do Paquistão e do Bangladesh, muitas vezes migrantes ilegais.
} 
os estrangeiros ser mobilizado a partir de baixo. E se os partidos políticos sul-africanos têm vindo a público condenar os ataques xenófobos como "atos vergonhosos", muitos são os políticos que defendem controlos fronteiriços mais rigorosos, especialmente em relação aos países vizinhos. Um outro elemento que caracteriza os ataques xenófobos sul-africanos tem a ver com o lugar e os atores que os provocam: estes ataques surgem maioritariamente em contextos de favelas, onde os sul-africanos negros competem com estrangeiros africanos, pelos meios de sobrevivências.

Em 2008 (e, de novo, em 2015), imagens de extrema violência surpreenderam o mundo, imagens em que africanos eram atacados por grupos exaltados de negros sul-africanos, ataques estes que tiveram lugar nas zonas mais pobres dos principais municípios sul-africanos. Estas imagens chocaram os países vizinhos, de onde eram oriundos muitos dos migrantes que pereceram (Nyamnjoh, 2016), e obrigaram-nos a pensar sobre esta realidade. É que estas cenas relembram os protestos anti-apartheid dos anos 1980, quando a polícia respondia com gás lacrimogéneo e dispersava as multidões recorrendo a balas de borracha. Como explicar estes atos de violência perpetrada por grupos de sub-humanos radicalmente excluídos do acesso a uma cidadania plena, sobre estrangeiros africanos abissalmente excluídos de serem sul-africanos? Como explicar esta violência, estas atitudes em relação a cidadãos de países que apoiaram resolutamente a libertação da África do Sul do regime hediondo do apartheid?

Sendo uma noção complexa e subjetiva, na sociedade sul-africana a xenofobia está intimamente ligada às dificuldades da transição económica; aos nacionalismo em tempos em que o significado de estado-nação não é claro; aos desafios suscitados pela globalização neoliberal, que trouxe uma mobilidade sem precedentes; e aos desafios das representações na história.

A vaga de trabalhadores migrante para a África do Sul, trabalhadores oriundos de países e regiões vizinhas, começou há mais de um século e 
continuou a funcionar após o fim do apartheid, com pequenas alterações (Harris, 1994; Nyamnjoh, 2006; Vidal, 2014). Mas o fim do apartheid sinalizou mudanças dramáticas nos fluxos migratórios internacionais na região austral do continente africano. Como Loren Landau argumenta (2005, p. 6), os novos padrões de imigração, embora continuem a garantir o funcionamento das minas e da agricultura (principais sectores económicos que se apoiam em força de trabalho migrante), mudaram em termos de destinos desta mobilidade. Pela primeira vez, as cidades tornaram-se o destino principal dos migrantes que aportam à África do Sul. Neste novo contexto, e com a África do Sul a constituir-se como a principal economia regional, o país tornou-se um destino apetecido para muitos africanos (e não só). Esta migração conhece uma grande variedade de formas: migrações de curto, médio e longo prazo; migrações documentadas e indocumentadas; migrações voluntárias e forçadas.

Nos dias de hoje, a África do Sul conta com cerca de 5 milhões de migrantes, maioritariamente oriundos dos vizinhos países africanos. Esta presença tem sido crescentemente vista como uma ameaça ao bem-estar e à segurança dos sul-africanos, o que abre campo para analisar as razões que subjazem a estes ataques xenófobos. A África do Sul, antes um país fechado e ostracizado pelos restantes países africanos governados por maiorias negras, tem-se tornado, como já sublinhado, um dos destinos preferenciais para um número sem precedentes de pessoas vindas de países africanos que atravessam realidades económicas e políticas conturbadas. Mas este influxo ocorreu em meio a transformações da economia doméstica que alteraram significativamente as relações entre o trabalho e o capital. Assistiu-se a uma drástica redução dos empregos - referida eufemisticamente como uma realidade de 'crescimento sem emprego', na qual a maioria dos desempregados é negra (Ndlovu-Gatsheni, 2007). Dados recentes apontam que, na sequência das políticas do governo do 
ANC, ${ }^{11}$ o desemprego subiu de 13\% por cento em 1994 para 25,5\% na atualidade, $^{12}$ (ou 40\% segundo fontes não-oficiais). De acordo com o Economist, ${ }^{13}$ metade dos sul-africanos com idade inferior a 24 anos não encontra emprego e entre os que têm emprego, um terço ganha menos de dois dólares por dia. Ainda digno de nota é o fato de muitos dos empregadores optarem crescentemente por mão-de-obra flexível, na sua maior parte executada por 'trabalhadores ilegais' mal pagos, vistos como essenciais para a sua sobrevivência em mercados competitivos (Buhlungu et al., 2006). Paradoxalmente, é o mesmo país cujo setor de mineração - a espinha dorsal de sua economia durante e no pós-apartheid -, é em grande parte sustentado por africanos estrangeiros.

Pesquisas realizadas na África do Sul mostram que os ataques xenófobos têm sido orquestrados por indivíduos ou grupos que buscam aumentar seu poder econômico ou político à custa de africanos estrangeiros, migrantes africanos que continuam a ser vistos como inferiores e atrasados. Este sentimento de animosidade é fruto de encontros contemporâneos dos habitantes das periferias das grandes metrópoles sul-africanas com estrangeiros considerados bem-sucedidos (Adam; Moodley, 2014, p. 61-63). O persistente ressentimento anti-imigrante, esta ideologia xenófoba, está também parcialmente enraizada na micropolítica dos municípios sul-africanos, a braços com elevadas taxas de desemprego, falta de acesso a moradia digna, eletricidade, água, saneamento básico, etc.

Como esta análise sugere, o maniqueísmo gerado pela relação colonial e pelo regime de apartheid - uma linha abissal que separava a comunidade branca da massa considerada sub-humana dos negros, coulored,

\footnotetext{
${ }^{11}$ Do inglês African National Congress. O ANC é o partido político dominante na cena sul-africana.

12 Informação disponível em http://www.statssa.gov.za/.

${ }^{13}$ Sad South Africa. Economist, edição de 20 out. 2012.
} 
indianos, etc. - permanece funcional. A alteração a assinalar tem a ver com a reconfiguração do grupo 'humano', que integra agora os governantes e elites políticas e económicas negras, coulored e indianas. Esta trama política alterou parcialmente os contornos da linha abissal, mas não a removeu. Em suma, a massa dos excluídos abissalmente é enorme. No regime de democracia liberal da África do Sul dos nossos dias, a estrutura social permanece bifurcada: de um lado estão os humanos, brancos e membros de uma classe média negra; do outro lado, onde está a maioria dos sul-africanos, a violência, a apropriação e a repressão ditam as regras de existência.

No centro do projeto de cidadania negra sul-africana - e que é usado como álibi por trás do qual os estrangeiros africanos são assediados, perseguidos e mortos por nenhuma outra razão que não seja serem não-cidadãos - encontra-se uma noção de negritude que se estrutura em vários graus de 'civilização' africana, como Francis Nyamnjoh discute na sua última obra (2016). Um exemplo desta separação é a marca tácita da superioridade do Inglês, uma língua colonial, muitas vezes apresentada como uma língua local e, muitas vezes usada como diferenciador chave entre o cidadão e o kwerekwere, entre o civilizado e o incivilizado.

Num outro momento, e como sublinham vários autores (Worby; Hassim; Kupe, 2008; Bond et al., 2011; Adam; Moodley, 2014), as transformações que a África do Sul conheceu desde o fim do apartheid assentaram em projetos e promessas utópicas de cidadania: todos seriam cidadãos, o que, transformado em projeto político, significava, para uma maioria significativa, a possibilidade de ser capitalista. Este horizonte de emancipação face à violência colonial surgia no cerne da promessa do ANC - no governo central e em muitos dos municípios - de que todos os sul-africanos podiam acumular, consumir e satisfazer os seus desejos reprimidos. Esta opção política merece uma reflexão, quer no caso sul-africano, quer no caso dos processos das independências africanas. É que 
estas transições não corresponderam a um corte radical com a situação colonial-capitalista. A liberalização e as condições neoliberais que se seguiram às independências e à chegada ao poder de governos de maioria negra têm estado associadas, em todo o subcontinente, ao crescimento - não esperado - da violência, do crime e da confusão. Os últimos anos têm sido marcados pelo fim dos discursos oficiais sobre futuros de igualdade, de garantia de trabalho para todos, e também das promessas de um governo protetor. Estes ideais cederam lugar a um espírito de desregulação, uma mistura cruel entre emancipação e limitação, entre regulação e violência (Bond et al, 2011).

Do acima exposto, torna-se óbvio que o fim do apartheid não significou o fim das desigualdades; não significou justiça social. A maioria negra, que pouco ou nada ganhou com a liberdade, têm agora que partilhar espaços sociais precários com gente africana que continua a ser classificada como 'de fora'. Estes que saíram a perder, e se consideram sul-africanos, têm expectativas em relação à responsabilidade do Estado sul-africano para com eles. Mas será a violência contra estrangeiros uma manifestação de protesto contra a indiferença do próprio Estado sul-africano perante a maioria dos seus cidadãos? E porque é que essa manifestação é dirigida logo contra estrangeiros africanos?

Uma das razões destes ataques prende-se com a ausência de um (re) conhecimento, por parte do cidadão comum sul-africano, da contribuição dos países vizinhos (com muito sacrifício humano, inclusive) para o fim do apartheid na África do Sul, como já referido. É que a África do Sul foi construída, enquanto estado-nação, a partir das referências eurocêntricas, como um país mais avançado, política e economicamente falando, que os territórios vizinhos. E a sequela desta presença colonial capitalista mantém-se: como já referido, o processo de construção da 'alteridade' continua a referir-se ao estrangeiro branco como o 'outro' desejado, en- 
quanto o estrangeiro africano é o 'outro' desprezível. Esses estereótipos são permanentemente (re)criados e (re)produzidos pela média, políticos, pelas elites e até mesmo pela sociedade civil (Pillay, 2008). Um outro conjunto de causalidade localiza-se ao nível do desenvolvimento da consciência política. Num texto excelente, Michael Neocosmos (2010) explica como o discurso hegemónico de valores políticos liberais, acriticamente aceito pelas elites políticas na África do Sul, está muito distante das ansiedades e desejos dos grupos mais desfavorecidos na África do Sul. Os estrangeiros africanos são muitas vezes perseguidos porque não podem 'violar' as condições do acordo liberal em que assenta a democracia sul-africana. É sobre este jogo de identidades agrupadas e etnias inventadas, apoiadas nas fundações maleáveis do projeto de cidadania estrangeira (fruto de uma divisão política criada pelos europeus na Conferência de Berlim de 1884-1885) que assenta o binário cidadão / kwerekwere.

Estas duas razões juntas explicam uma África do Sul embaraçada com os países vizinhos, uma África do Sul que se assume mais avançada, moderna, e que se procura afastar da imagem de pobreza e barbárie que supostamente caracteriza os restantes países da região austral do continente. A questão económica joga igualmente um papel decisivo. A subida dramática do custo de vida nos espaços urbanos tem gerado ondas de violência pelo mundo inteiro. Na África do Sul, a gramática liberal democrática dominante insiste numa leitura colonial etnicizada e racial destes problemas. Os 'não-cidadãos' são os makwerekwere, descritos como o 'mal da cidade' porque usurpam empregos e recursos. A onda nativista sul-africana vê no estrangeiro - a corporificação da ameaça ao trabalho e ao bem-estar - um modo persuasivo de confrontar a fraqueza económica constante. Assim é que estrangeiros - e em particular estrangeiros negros - têm-se tornado cada vez mais objeto de contestação especialmente nos espaços urbanos, cruzando todo o espectro político - dos partidos polí- 
ticos, aos meios de comunicação social, até vendedores de rua e desempregados. Os 'ilegais', africanos negros, são acusados de drenar a riqueza da nação sul-africana, num contexto onde a raça e a tribo são gramáticas do quotidiano que significam e simbolizam conflitos sociais e de interesses (Park, 2009; Bond et al, 2011; Nyamnjoh, 2016). Ou seja, a separação entre os que estão dentro da cidadania e os que estão fora serve um duplo propósito: primeiro, como bodes expiatórios, os makwerekwere ajudam a manter a legitimidade do projeto pós-apartheid, ao possibilitar explicações convenientes que 'ajudam' a explicar o aumento do crime, de desemprego, instabilidade social, etc. Mais ainda, um estrangeiro desumanizado e homogéneo 'outro' acentua a ligação dos sul-africanos dentro do espaço nacional. Através do nativismo emergente, as populações negras das grandes metrópoles procuram um sentido para requerer a sua inclusão na nação pós-apartheid. Neste sentido, a reivindicação nativista sul-africana mostra como o evocar do estado nacional funciona como principal instrumento de inclusão e exclusão entre os sul-africanos e os 'outros', os makwerekwere.

A identidade nacional, a cidadania política, longe de serem equalizadores incontestados, são campos onde a experiência da desigualdade é revisitada, questionando, de modo profundo, as identidades e as pertenças. Na África do Sul pós-apartheid, a afronta ao estrangeiro forneceu um argumento versátil de aliança, unindo um povo há muito dividido pela raça, pelas diferenças étnicas, pela classe: foi um instrumento mobilizado por aqueles que buscam evocar uma nação nova, não apenas construindo uma ponte sobre antinomias já conhecidas, mas erguendo fronteiras finitas sob condições que, aparentemente, ameaçam aniquilar a viabilidade do estado-nação (Neocosmos, 2010). O que estes discursos traduzem, de facto, é uma insistência na despolitização da política, no tratamento do 'outro' como inimigo, a insistência, tal como no tempo do 
Sociologias, Porto Alegre, ano 18, no 43, set/dez 2016, p. 176-206

apartheid, do estereótipo do negro estrangeiro como bárbaro, à espera de ser civilizado pela excecionalidade sul-africana.

\section{A tradução intercultural como possibilidade para o ampliar de uma cidadania política mais ampla?}

As categorias produzidas pela modernidade, como identidade nacional, etnicidade, cidadania, democracia, foram historicamente construídas durante o encontro colonial, estando, por isso mesmo, imbuídas das relações de violência que este encontro gerou. A questão que se coloca, pois, é sobre os sentidos do conceito de cidadania e os seus antecedentes coloniais. Tal como proposto pelas autoridades coloniais, a cidadania política era exclusiva e não inclusiva, uniracial e não multiracial. Inspirava-se nas ideias do início do século XIX sobre a nacionalidade, naturalizando a ideia de Estado-nação. Um resultado importante deste processo foi a essencialização das nações, apresentando-se as populações nacionais como ligadas pela história, cultura, língua ou crença, fazendo coincidir a cidadania política com a cidadania cultural e económica. Mas esta situação não mudou radicalmente com o fim do apartheid; as hierarquias raciais, étnicas e simbólicas continuam presentes em muitos cenários contemporâneos. Tal como no passado, os políticos e as elites utilizam o poder do prestígio social, para classificar, excluir e subordinar aqueles que creem ser inferiores (Meneses, 2009).

Os discursos e apelos nativistas, ao criarem uma cortina de fumo que não permite traduzir saberes para além da gramática gerada pela colonização, ocultam do resto do mundo questões reais africanas, como os ataques xenófobos. Situações como as descritas para a África do Sul apontam a necessidade de redefinição dos contornos da comunidade política, assim como dos conteúdos e das formas de cidadania. Na sua essência, 
as lutas pelo alargamento da pertença como iguais são lutas fundamentais pela justiça cognitiva - falar-se como iguais, a partir de si mesmos.

Como continuidade da gramática colonial, os discursos nativistas xenófobos, pouco específicos e voláteis no seu conteúdo, acomodam prontamente 'uma mudança de um outro para outro', permanecendo muito suscetíveis à manipulação política. Enquanto a maior parte dos africanos vive como cidadãos em Estados, eles tendem a ser apenas condicional, parcial e situacionalmente cidadãos de Estados, pois a noção de cidadania é percebida de forma muito redutora. As práticas de reivindicação anti-imigrante têm como alvo preferencial os elementos socialmente mais frágeis - minorias e migrantes -, em lugar de se questionar o papel das elites políticas e económicas na melhoria das condições de destinos dos habitantes desses espaços, desses países. Estes discursos encontram um alvo fácil nos grupos migrantes vulneráveis, acusados de fomentar o crime, a prostituição, a falta de empregos, as doenças. É neste aspeto que as lutas contra a xenofobia - como descrita no caso sul-africano - encontram pontos de contacto com a violência racial que marca o Brasil, onde os negros continuam a reivindicar a abertura plena da noção de cidadania, para integrar outras perspetivas e saberes.

Pela sociologia das ausências (Santos, 2002), como marco teórico e metodológico, é possível analisar as limitações, incompletudes e ausências do processo de 'descolonização' em vários pontos do mundo, ao mesmo tempo que estas proposta aponta possibilidades de resistência e de superação da relação colonial, a partir de leituras que dão primazia a experiências situadas, fundamentais para uma tradução intercultural. Nesta proposta, a tradução é em si mesma um desafio histórico, uma questão de prática, uma negociação intercultural das histórias de lutas.

A comparação entre a violência no Brasil, marcadamente racial, e a violência xenófoba obriga a um conhecimento das experiências coloniais- 
-capitalistas e das suas latências, procurando produzir histórias em rede, nas quais as lutas se traduzem através de um conhecimento sofisticado das realidades que geraram estas violências, recuperando a humanidade do projeto pan-africano. Insistir-se numa proposta analítica singular - racismo - não dá conta de outros conflitos legados pela relação colonial, como é o caso da violência xenófoba. Só uma leitura comparada destes conflitos permite detetar o desdobramento das práticas de inclusão ou exclusão. Nas zonas de contacto intercultural, a partir de perspetivas diferentes, é possível desafiar as experiências, produzindo exercícios da tradução, com o objetivo de identificar, explicar e avaliar o que é comum na diversidade. Estes exercícios são fundamentais para, em cada dado espaço-tempo, determinar quem, numa dada situação de poder, está numa situação desigual, inferior, de poder. Estes horizontes permitem articular comparações, a partir da singularidade e da diferença, as quais, seguindo a proposta de Boaventura de Sousa Santos (2006), são vistas como uma condição através da qual a diversidade é vivida - não como fator de fragmentação e isolamento, mas como uma condição de partilha e solidariedade, como meios de alargar e aprofundar o diálogo intercultural entre formas e processos de conhecimento. A tradução intercultural, como proposta metodológica, revela o Sul global como um conjunto de epistemologias extremamente dinâmicas.

A necessidade, como projeto de mudança radical, de uma epistemologia radicada nas experiências do Sul global está assente numa nova noção de direitos, que promova, entre vários objetivos, a coexistência de culturas e de sistemas de saberes, tratados com dignidade. É assumir o pan-africanismo como prática. A justiça cognitiva, enquanto nova gramática global, contra-hegemónica, reclama, acima de tudo, a urgência da visibilidade de distintas formas de conhecer e experimentar o mundo, especialmente dos saberes marginalizados e subalternizados. É nesta linha 
que a proposta das Epistemologias do Sul é fonte para uma articulação e tradução dos saberes que constituem e dão sentido as estas lutas.

Para romper com os estereótipos e exotizações associados aos estudos sobre a contribuição dos negros na construção das sociedades americanas, de que o Brasil é exemplo, urge, como sublinha Nilma Gomes (2010, p. 495) ampliar os diálogos com os intelectuais comprometidos brasileiros, intelectuais que produzem um conhecimento que tem como objetivo dar visibilidade a subjetividades, desigualdades, silenciamentos e omissões em relação a determinados grupos sócio-raciais e suas vivências. Esta reflexão sublinha que as novas propostas epistemológicas devem incidir não nos conhecimentos em abstrato, mas nas práticas de conhecimento e seus impactos noutras práticas sociais (Santos, 2006, p. 154). A partir da proposta de se traduzirem lutas a partir de realidades concretas, e tendo em atenção a historicidade das sociedades africanas de onde veio a maioria dos negros brasileiros, é possível estabelecer um diálogo profundo entre matrizes africanas e expressões culturais africanas e afro-brasileiras. $\mathrm{O}$ alargamento epistémico à diversidade - as epistemologias do Sul - , propõe uma refundação radical da relação entre o epistemológico, o ontológico e o ético-político a partir de práticas, experiências e saberes que definem os limites e as condições em que um dado modo de conhecimento pode ser traduzido, transformado ou apropriado em novas circunstâncias, sem classificar nenhum deles como saber universal ou único.

O presente pós-colonial faz-nos a nós, africanos, contemporâneos deste mundo; ao mesmo tempo, é um ponto de interrogação, um ponto de vantagem diferente, uma nova perspetiva analítica que permite revisitar o passado e o futuro. O desafio atual tem no seu cerne a possibilidade de construção de uma sociedade política e de uma estrutura política capazes de dar aos cidadãos uma visão coerente e transformadora do seu passado; é um desafio por uma cidadania cultural ativa, que luta pela 
presença das histórias silenciadas como parte da dos projetos identitários em curso. A exigência de democratizar a democracia, do alargamento da participação cidadã, do direito, da prosperidade e da cidadania não podem dissolver-se em conflitos e recriminações, no caos político, como que justificando a impossibilidade de os africanos serem cidadãos, de poderem exercer o direito de voto, e de decidirem sobre si e as suas contribuições aos processos identitários. Um pouco por todo o continente, surgem exigências de uma cidadania mais ampla, cosmopolita; um esforço para acolher utopias para além do cânone estreito e limitador do moderno Estado-nação. ${ }^{14}$ Estes desafios são fundamentais para o futuro de África e as suas diásporas. E só serão resolvidos se pudermos começar a pensar de forma radical sobre uma interculturalidade cosmopolita, a partir da exigência de descolonização dos sabres e do sentido de ser. Ambas as tarefas não podem evitar um confronto com a ideia colonial. É a partir deste ponto de vantagem diferente, repleto de conhecimentos e experiências, que é possível decifrar as pistas da transição para outros mundos possíveis.

Maria Paula Meneses é Doutora em Antropologia pela Universidade de Rutgers (EUA) e Mestre em História pela Universidade de S. Petersburgo (Rússia). É investigadora coordenadora do Centro de Estudos Sociais da Universidade de Coimbra, Portugal. $\gg$ menesesp@ces.uc.pt

\footnotetext{
${ }^{14}$ Veja-se a este respeito o recente debate (2016) sobre a possibilidade de admissão do Haiti na União Africana (uma associação política continental).
} 
Sociologias, Porto Alegre, ano 18, no 43, set/dez 2016, p. 176-206

\section{Referências}

1. ADAM, H; MOODLEY, K. Imagined Liberation: Xenophobia, Citizenship, and Identity in South Africa, Germany, and Canada. Stellenbosch: Sun Press, 2014.

2. AMIN, S. El Eurocentrismo: crítica de una ideología. México: Siglo Veintiuno, 1989.

3. BALIBAR, E. We, the People of Europe? Reflections on Transnational Citizenship. Princeton: Princeton University Press, 2004.

4. BHABHA, H. K. The Location of Culture. London: Routledge, 1994.

5. BOND, P. et al. Xenophobia and Civil Society. Politikon, v. 38, n. 1, p. 59-83, 2011.

6. BRANDÃO, A. A. (Org.). Cotas raciais no Brasil: a primeira avaliação. Rio de Janeiro: DP\&A, 2007.

7. BUhlunGU, S. et al. (Org.). State of the Nation: South Africa 2005-2006. Cape Town: HSRC Press, 2006.

8. CÉSAIRE, A. Cahier d'un retour au pays natal. Paris: Bordas, 1947.

9. FANON, F. The Wretched of the Earth. New York: Grove Press, 1963 [1961].

10. FANON, F. Black Skin, White Masks. New York: Grove Press, 1967 [1952].

11. GEERTZ, C. Thick Description: Toward an Interpretive Theory of Culture. In: GEERTZ, C. The Interpretation of Cultures: Selected Essays. New York: Basic Books, 1973. p. 3-30.

12. GILROY, P. True Humanism? Civilisationism, Securitocracy and Racial Resignation. Johannesburg Workshop in Theory and Criticism, v. 1, 2009. Disponível em: http://jwtc.org.za/resources/docs/Salon-1-pdfs/Gilroy_TrueHumanism_.pdf. Acesso em: 27 dez. 2015.

13. GOMES, N. L. Intelectuais Negros e Produção do Conhecimento: Algumas Reflexões sobre a Realidade Brasileira. In: SANTOS, B. S.; MENESES, M. P. (Org.). Epistemologias do Sul. São Paulo: Cortez, 2010. p. 492-516.

14. GOMES, N. L. Relações Étnico-Raciais, Educação e Descolonização dos Currículos. Currículo sem Fronteiras, v. 12, n.1, p. 98-109, 2012.

15. GRAMSCI, A. Prison Notebook, Volume 2. New York: Columbia University Press, 1996 [1948].

16. HARRIS, P. Work, Culture and Identity: Migrant Laborers in Mozambique and South Africa c. 1860-1910. Johannesburg: Witwatersrand University Press, 1994. 
Sociologias, Porto Alegre, ano 18, no 43, set/dez 2016, p. 176-206

17. HOUNTONDJI, P. Combats pour le sens. Un itinéraire africain. Cotonou: Flamboyant, 1997.

18. LANDAU, L. B. Urbanization, nativism and the Rule of Law in South Africa's 'Forbidden' Cities. Vancouver: Vancouver Centre of Excellence, Working Paper Series n. 05-05, 2005.

19. MBEMBE, A. African Modes of Self-Writing. Public Culture, v. 4,n. 2, p. 239273, 2002.

20. M’BOKOLO, E. África negra: história e civilizações (vol. 1). Lisboa: Vulgata, 2003.

21. MENESES, M. P. O 'indígena' africano e o colono 'europeu': a construção da diferença por processos legais. E-cadernos CES, Coimbra, v. 7, p. 68-93, 2009.

22. MENESES, M. P. Images Outside the Mirror? Mozambique and Portugal in World History. Human Architecture, v. 9, p. 121-137, 2011.

23. MENESES, M. P. Os sentidos da descolonização: uma análise a partir de Moçambique. Opsis, v. 16, n. 1, p. 26-44, 2016.

24. MUDIMBE, V. Y. The Invention of Africa. Gnosis, Philosophy and the Order of Knowledge. Bloomington: University of Indiana Press, 1988.

25. MUNANGA, K. Rediscutindo a mestiçagem no Brasil: Identidade Nacional versus Identidade Negra. Belo Horizonte: Autentica, 2004.

26. NCUBE, T. I fear for the future here in South Africa. Mail \& Guardian. Opinion, 08 May 2015. Disponível em http://mg.co.za/article/2015-05-07-i-fear-forthe-future-here-in-south-africa. Acesso: 8 maio 2015.

27. NDLOVU-GATSHENI, S. J. Tracking the historical roots of post-apartheid citizenship problems: the Native Club, restless natives, panicking settlers and the politics of nativism in South Africa. Leiden: ASC Working Paper n. 72, 2007.

28. NEOCOSMOS, M. From 'Foreign Natives to Native Foreigners': Explaining Xenophobia in a Post-Apartheid South Africa. Dakar: CODESRIA, 2010.

29. NKRUMAH, K. I Speak of Freedom: A Statement of African Ideology. London: Heinemann, 1961.

30. NYAMNJOH, F. Insiders and Outsiders: Citizenship and Xenophobia in contemporary Southern Africa. Dakar: CODESRIA, 2006.

31. NYAMNJOH, F. \#RhodesMustFall: Nibbling at resilient colonialism in South Africa. Mankon: Langaa Research and Publishing, 2016.

32. PARK, A. A Tale of Two Townships: Political Opportunity and Violent and Non-Violent Local Control in South Africa. Award Winning Sociology Papers, n. 1, 2009. 
33. PILLAY, S. Dangerous Ordinary Discourse: Preliminary reflections on xenophobia, violence and the public sphere in South Africa. Trabalho apresentado à 12 a Assembleia Geral do CODESRIA realizada entre 7-11 Dez. 2008 em Yaoundé, Camarões.

34. RAMOSE, M. B. African Renaissance: a northbound gaze. In COETZEE, P. H.; ROUX, A.P.J. (Org.). The African Philosophy Reader. London: Routledge, 2003. p. 600-610.

35. SANTOS, B. de S. Para uma sociologia das ausências e uma sociologia das emergências. Revista Crítica de Ciências Sociais, v. 63, p. 237-280, 2002.

36. SANTOS, B. de S.. A gramática do tempo: para uma nova cultura política. São Paulo: Cortez, 2006.

37. SANTOS, B. de S. Para além do Pensamento Abissal: Das linhas globais a uma ecologia de saberes. Revista Crítica de Ciências Sociais, v. 78, p. 3-46, 2007.

38. SANTOS, B. de S. The World Social Forum and the Global Left. Politics \& Society, v. 36, n. 2, p. 247-270, 2008.

39. SANTOS, B. de S.; MENESES, M. P. Introdução. In: SANTOS, B. S.; MENESES, M. P. (Org.). Epistemologias do Sul. São Paulo: Cortez, 2010. p. 7-17.

40. SANTOS, B. de S. Epistemologies of the South. Justice against Epistemicide. Boulder: Paradigm, 2014.

41. SILVA, P. B. G.; SilvériO, V.; BARBOSA, L. M. A. (Org.). De Preto a AfroDescendente. São Carlos: EdUSFCAR, 2003.

42. THIONG'O, N. w. Moving the Centre. The Struggle for Cultural Freedoms. London: James Currey, 1993.

43. VIDAL, D. Migrants du Mozambique dans le Johannesburg de I'aprèsapartheid. Travail, frontières, altérité. Paris, Johannesburg: Karthala-IFAS, 2014.

44. WORBY, E.; HASSIM, S.; KUPE, T. (Orgs.). Go Home or Die Here: Xenophobia and the Reinvention of Difference in South Africa. Johannesburg: Wits University Press, 2008.

Recebido em: 12.01.2016

Aceite: 31.03 .2016 